\title{
Green Supply Chain Management Using the Queuing Theory to Handle Congestion and Reduce Energy Consumption and Emissions From Supply Chain Transportation Fleet
}

\author{
Arvin Aziziankohan ${ }^{1}$ (D), Fariborz Jolai ${ }^{2}$ (D), Mohammad Khalilzadeh ${ }^{1}$ (D), \\ Roya Soltani ${ }^{1}$ (D), Reza Tavakkoli-Moghaddam ${ }^{2}$ \\ ${ }^{1}$ Department of Industrial Engineering, Science and Research Branch, Islamic Azad University, Tehran (Iran) \\ ${ }^{2}$ School of Industrial Engineering, College of Engineering, University of Tehran, Tehran, (Iran) \\ arvin.azizian@gmail.com,fjolai@ut.ac.ir,mo.k.zadeb@gmail.com,roya.soltani@gmail.com,tavakoli@ut.ac.ir
}

Received: November 2016

Accepted: February 2017

\section{Abstract:}

Purpose: Nowadays, governments and people pay more attention to use green products due to environmental pollution, irreplaceable energy and shortage of resources. Green products are resulted from the application of green supply chain management strategies to the organizations' performance strategies, so that we can reduce environmental pollutants and wastes and take a step towards saving energy with limited resources.

Design/methodology/approach: In this paper, the effect of reducing energy consumption in green supply chain is examined by using queuing theory and transportation models. Data was generated and solved by a commercial optimization epackage.

Findings: The findings indicate that suitable assignment of existing transportation fleet with specified capacity, and using queueing theory in a closed-loop network to reduce the queue length and handle congestion, can cause a reduction in energy consumption by optimizing transportation and waiting times in a green supply chain.

Originality/value: Adopting investment strategy in improving the environmental performance of the supply chain, will yield in many advantages and benefits. This article investigates the effect 
of queuing theory on reducing waiting time and optimizing energy consumption in green supply chain.

Keywords: green supply chain, green supply chain management, queuing theory, LINGO, closed-loop supply chain, congestion

\section{Introduction}

Globalization, increased regulation of governmental and non-governmental organizations and pressure and demands of customers regarding environmental issues, has caused the reviewing required measures to use the green supply chain management by the organizations to improve environmental and economic performance. Green supply chain management integrates of supply chain management with environmental requirements at all stages of product design, selection and supply raw material, production and manufacturing, distribution and transmission processes, delivery to the customer and after consumption processes such as recycling and reuse management in order to maximize the amount of energy and resource efficiency, along with improved performance of the entire supply chain (Olfat, Khatami-Firouz \& Khodaverdi, 2011).

Green supply chain management ( $\mathrm{GrSCM})$, is a topic extracted from the perspective of the traditional supply chain (Fortes, 2009). Quality revolution in the late 1980s and revolution of supply chain in the late 1990s led businesses to the environmental sensitivity (Srivastava, 2007). This topic was popularized gradually in the community. Environmental efficiency and reproduction processes, are now important assets to achieve the best practices (Ashley, 1993; Srivastava, 2007). Kelle and Silver (1989) were among the researchers who examined green supply chain management as an applied issue and proposed a system for the products that are potentially reusable for the organizations. Navin-Chandra (1991) for the first time, proposed the need for green design concept to reduce the impact of product waste. Then Ashley (1993), Allenby and Richards (1994), Zhang, Kuo, Lu and Huang (1997) have developed green design. De Ron and Penev (1995), Beamon (1999) and Arena, Mastellone and Perugini (2003) considered the product life cycle analysis as a framework for green design. Reverse logistics, is another area of green marketing that many studies have been done about it. Among the scholars who conducted case studies in the field of green marketing, Pohlen and Farris (1992), Stock (1998), Carter and Ellram (1998), Shih (2001), Tibben-Lembke (2002), Srivastava and Srivastava (2006), Nagorney and Toyasaki (2005) and Min, Ko and Ko (2006) can be noted. 
Waste Management is another concept that lies at the heart of green supply chain management. Roy and Whelan (1992) were the first researchers who have worked in this field. They proposed a model for reduction of electronic waste. Other researchers such as Hannah and Newman (1995), Sarkis and Cordeiro (2001) and Nagorney and Toyasaki (2005) focused on the recovery and reproduction.

Green manufacturing concept was introduced in 1993 by Crainic et al. they suggested a green supply chain model by sea freight containers (Fortes, 2009). The concept of green manufacturing was continued by Van Der Laan and Salomon (1997), Guide and Srivastava (1998) and White, Masanet, Rosen and Beckman (2003) research.

Green supply chain is the set of firm's internal and external actions throughout the supply chain, to improve the environment and prevent pollution (Nasseri-Taheri, 2006). In other words, green supply chain management includes green purchasing, green production, green distribution, green marketing and reverse logistics. Rao and Holt (2005) suggest that the concept of green supply chain management includes the following environmental initiatives:

1. Internal logistics;

2. Production or internal supply chain;

3. External logistics;

Reverse Logistics which includes activities in which the raw material suppliers, service contractors, dealers, distributors and end users together, try to reduce or eliminate the harmful environmental effects of their work. According to Srivastava (2007) green supply chain, taking into account environmental issues in supply chain management, is defined including product design, selection and sourcing of materials, manufacturing process, the final product delivered to the customer and product management after consumption and elapsing useful life.

Generally, it is inferred that green supply chain management, enhances the efficiency and synergy between commercial partners and their leader companies, to help increase environmental performance, minimizes waste and saves costs. It is expected that the synergy, improve the competitive advantage and marketing image and (Rao \& Holt, 2005). Thus, supply chain management results in the certain financial and operating interests (Bowen, Cousins, Lamming \& Faruk, 2001).

The managers of green supply chain in leading companies are trying to use green logistics and satisfaction by creating environmental perspective throughout the supply chain, improving the environmental performance in the entire supply chain as a strategic weapon for gaining competitive advantage and founded they objectives on three important topics: green design (product), green manufacturing (process) and recycling products, (Boks \& Stevels, 2007). 


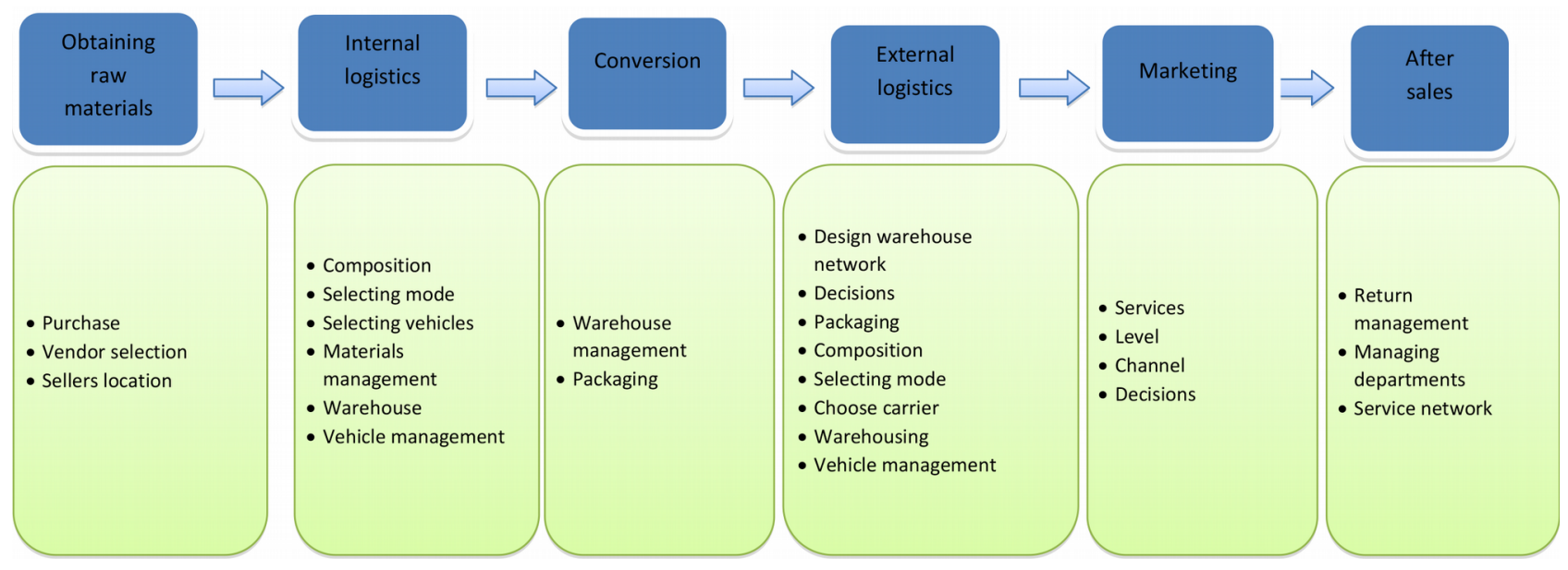

Figure 1. Green supply chain management (Wu \& Dann, 1995)

Green supply chain management integrates the supply chain management and environmental requirements at all stages of product design, selection, supply of raw materials, manufacturing, transportation and distribution processes, and finally, processes after consumption such as recycling and reuse management, in order to maximize the productivity of energy and resources as well as improving the entire supply chain (Sarkis, 2006).

Amemba, Nyaboke, Osoro and Mburu (2013) modeled the components of green supply chain based on the Heravani, Nemati, Bozorgipour and Hosseininegad (2005) model, as Figure 2.

\begin{tabular}{|c|}
\hline Green purchasing \\
\hline Green design \\
\hline Green operation and reverse logistics \\
\hline Green manufacturing \\
\hline Waste management \\
\hline
\end{tabular}

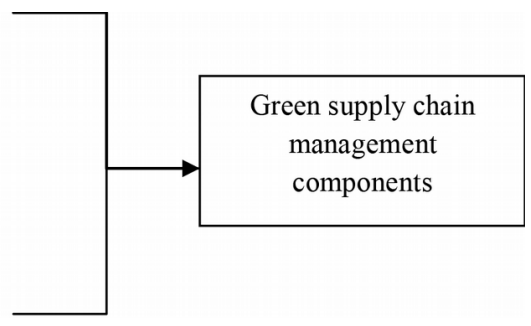

Figure 2. Green supply chain management components (Heravani et al. (2005))

The results obtained from Amemba et al. (2013) illustrate that organizations should enhance the implementation level of green supply chain practices in managing their operations. 


\section{Problem Statement}

Today, ensuring the sustainable development of any country is subjected to the conservation and efficient use of limited and irreplaceable resources in that country; various measures are done to deal with this issue by governments including applying green laws and principles, such as the use of environmentally friendly raw materials and industrial centers of production, reducing the use of fossil energy and oil resources, recovering paper and reuse of waste. Extending government regulation to obtain environmental standards and the growing consumers' demand for green products in supply chain, which contains all activities related to the flow of goods, from raw material stage to the delivery of goods to final consumers using information flow throughout chain, causes the emergence of a new concept of green supply chain management. Adopting investment strategy in improving the environmental performance of the supply chain, will result in many advantages and benefits such as saving energy, reducing emissions, eliminating or reducing the waste, creating value for customers and, ultimately, increasing productivity for the manufacturing and services companies (Imani \& Ahmadi, 2009). This article will investigate the effect of queuing theory on reducing waiting time and optimizing energy consumption in green supply chain.

\section{Managing Traffic Congestion Using Queuing Theory}

Concentrating on two concepts of traffic congestion and uncertainty, each can be divided into two categories.

Traffic congestion is defined as a situation in which the average speed of traffic is less than the minimum speed in a free flow network (Sadjadi, Soltani \& Eskandarpour, 2014).

In this paper, congestion can stemmed from some endogenous and exogenous factors and each of proposed models is considered under stochastic and fuzzy uncertainties (Fathian, Jouzdani, Heidari \& Makui, 2016).

In general, people do not want to wait; however, reducing the waiting time usually requires additional investment. To decide about whether or not to invest, it is important to understand the impact of investment on waiting time (Adan \& Resing, 2002). How to balance our efficiency and cost? Here is the time that queuing theory is introduced to solve the problem. The queuing theory includes mathematical study of waiting queues and stochastic random processes related to it. A queuing system can be defined for customers to receive input service and if the service is not available, wait for it. Important areas of application of queuing models include production systems, storage and transportation systems, 
communication systems and information processing systems. Queuing models designed for these systems are practical in terms of design, capacity and control (Adan \& Resing, 2002).

Forming a queue is a social phenomenon that if it can be managed in such a way that both the unit and the person, who provides the service, earn the greatest possible benefit, it is beneficial to society. In queuing theory, the applicant, whether human or the other thing, is considered as the customer and the service provider is known as servers.

Queue length, customer's average waiting time in queue and server idle time percent are among the queuing system evaluation criteria.

In accordance with the above explanation, it is clear that each sub-process of green supply chain acts as a queuing system. For example, if we assume the organizations applicant for buying raw materials as the customer and the supplier of the raw materials as servers, it is possible to use queue problem solving approaches as efficient methods. Different organizations request raw materials and certainly also expect that receive the service(raw materials) during a certain timeframe. Server can prioritize the organizations based on his records and policies and provide customer service, under different conditions; this is while, we recognize the specific capacity for the supplier and the speed of service providing is also measurable; since the process of green purchase allows evaluation by measuring the average waiting time for each organization to get raw materials or the queue length. The above analysis can be used to check each of green production processes, distribution and marketing as well.

As presented in Table 1, despite the useful application of the queueing theory in handling congestion, the literature of queue in congestion is rarely surveyed. In this paper the queueing theory is employed to handle congestion and decrease the transportation time and finally reduce environmental pollutions in a green supply chain framework. 


\begin{tabular}{|c|c|c|c|c|c|c|c|c|c|}
\hline \multirow[t]{2}{*}{ Article } & \multirow[t]{2}{*}{$\operatorname{Tr}$} & \multirow[t]{2}{*}{ Net } & \multicolumn{3}{|c|}{ Congestion factor } & \multicolumn{2}{|c|}{$\begin{array}{l}\text { Kind of } \\
\text { pricing }\end{array}$} & \multirow[t]{2}{*}{ Un } & \multirow[t]{2}{*}{ Queue } \\
\hline & & & $\mathrm{Ca}$ & De & Un & Pco & Co & & \\
\hline Chen, Xiong, He, Zhu and Zhang, 2016 & $\checkmark$ & $\checkmark$ & & $\checkmark$ & & $\checkmark$ & & & \\
\hline $\begin{array}{l}\text { Chiu, Bottom, Mahut, Paz, Balakrishna, Waller } \\
\text { and Hicks, } 2011\end{array}$ & $\checkmark$ & & & & & $\checkmark$ & & & \\
\hline Friesz, Bernstein and Kydes, 2004 & $\checkmark$ & & & $\checkmark$ & & $\checkmark$ & & & \\
\hline Zhang, Rossi and Pavone, 2016 & & $\checkmark$ & & $\checkmark$ & & & & $\checkmark$ & $\checkmark$ \\
\hline $\begin{array}{l}\text { Rahimi, Tavakkoli-Moghaddam, Mohammadi } \\
\text { and Sadeghi, } 2016\end{array}$ & $\checkmark$ & $\checkmark$ & $\checkmark$ & & & $\checkmark$ & & & $\checkmark$ \\
\hline Zangui, Yin and Lawphongpanich, 2015 & $\checkmark$ & $\checkmark$ & $\checkmark$ & $\checkmark$ & & & & & \\
\hline Berman and Krass, 2015 & $\checkmark$ & $\checkmark$ & $\checkmark$ & $\checkmark$ & & & & $\checkmark$ & \\
\hline Vass and Szabo, 2015 & & & $\checkmark$ & & & & $\checkmark$ & & $\checkmark$ \\
\hline Ding, Tang and Ji, 2016 & & $\checkmark$ & $\checkmark$ & & & & & & $\checkmark$ \\
\hline Fathian et al., 2016; Jouzdani and Fathian, 2016 & $\checkmark$ & & $\checkmark$ & $\checkmark$ & & & & $\checkmark$ & \\
\hline $\begin{array}{l}\text { Geramianfar, Pakzad, Golhashem and } \\
\text { Tavakkoli-Moghaddam, } 2013\end{array}$ & $\checkmark$ & $\checkmark$ & $\checkmark$ & & & & & & \\
\hline Ernst and Krishnamoorthy, 1996 & $\checkmark$ & $\checkmark$ & $\checkmark$ & & & & $\checkmark$ & & \\
\hline Kian and Kargar, 2016 & & $\checkmark$ & $\checkmark$ & & & & $\checkmark$ & & \\
\hline Inoue, Miyashita and Sugita, 2016 & $\checkmark$ & $\checkmark$ & & $\checkmark$ & & & $\checkmark$ & $\checkmark$ & \\
\hline
\end{tabular}

De: Demand, Tr: Traffic, Pco: Price congestion, Co: Cost, Un: Uncertainly, EF: External factor.

Table 1. Congestion 


\section{Types of Queue Systems Based on the Physical Layout}

In this classification, Queue systems are analyzed based on two factors of input channel and server (Gupta \& Khanna, 2006). The simplest queuing system includes an input channel to entry customers as well as a server. This system is called single channel and single server. In most complex state, the queuing system consists several input channels and multiple servers-that offer different services. This system is known as multi-channel system and multi-servers system. The general types of queuing system, in terms of physical layout, are shown in the figures below:

1. Single-channel and single-server system

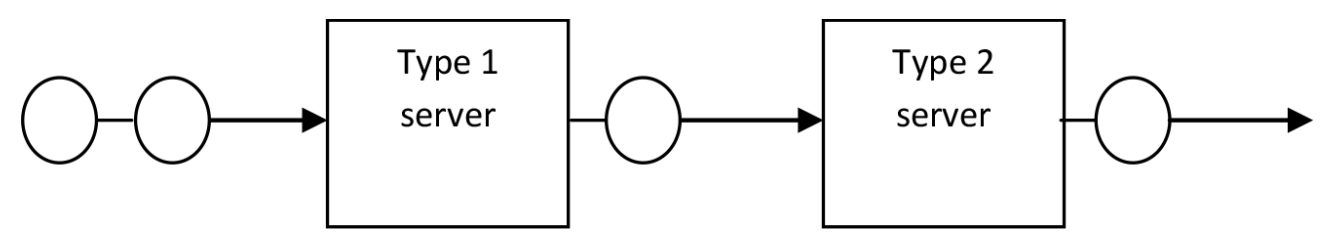

2. Single-channel and multiple servers system

3. Multiple and single server system

4. Multiple systems and servers

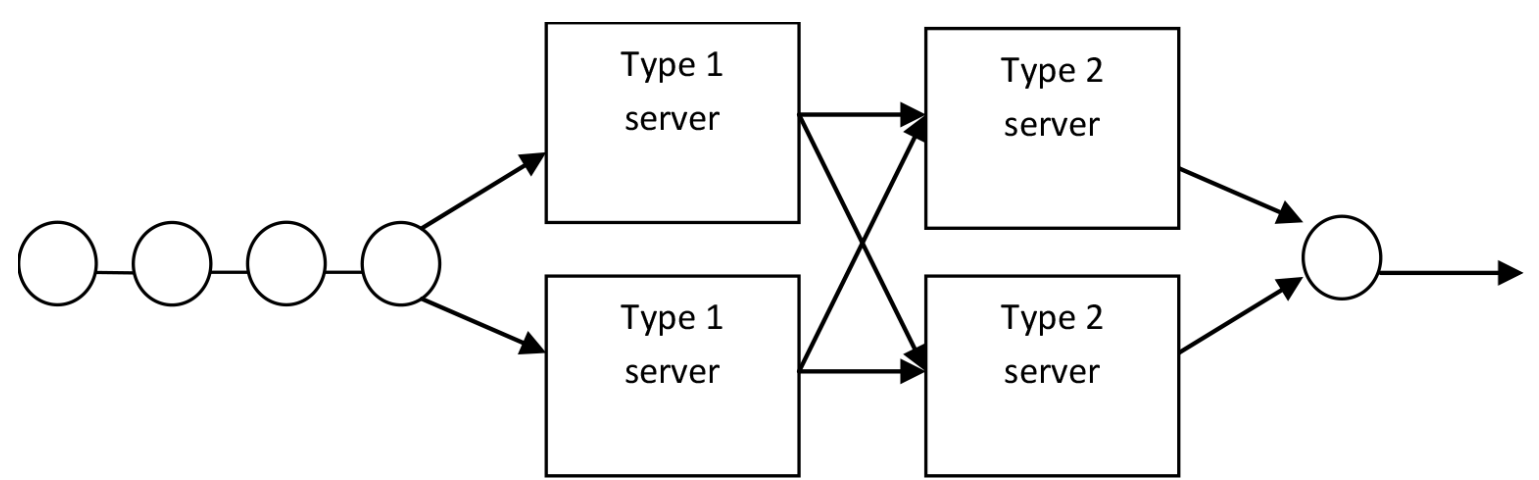

Figure 3. Types of Queue systems (Abedi, Hamidi \& Parkhan, 2011) 


\section{Queuing Process Features}

Process of Customer arrival: Customers may enter individually or in batches (Adan \& Resing, 2002). Login process is often considered as arrival rate that is the average number of entries per second (Stallings, 2000). Intervals between two inputs are usually considered independent (Adan \& Resing, 2002). Distribution that is considered for entry process includes exponential distribution, Deterministic distribution and binomial distribution.

Customer behavior: The client may be patient and willing to wait (for long time) or client may not be patient and leave the place after a while (Adan \& Resing, 2002).

Service time: when a unit is assigned to a given channel, the time that takes to get the same service, may be a fixed or variable time (Jafarnejad, 1991). This component is the average service time to each input excluding waiting time in Queue (Stallings, 2000). Service time can be considered as depend on the length of Queue (Adan \& Resing, 2002).

The number of servers: there may be a single or multiple servers for serving customers.

The system capacity (waiting room): Due to limited number of customers in the system, the restriction can exist in the waiting room (Adan \& Resing, 2002). This means that if there are $m$ servers and there is no more waiting room, $\mathrm{m}$, is considered as system capacity. The system capacity component is not considered for the unlimited waiting room.

Population size: the number of customers, who come in for service, makes up the population size.

Queue order: customers can be served individually or in batches (Adan \& Resing, 2002). There are various possibilities for service order:

FCFS (First Come First Serve): where the customer who comes first is served soonest.

LCFS (Last Come First Serve): where every client who comes last is served soonest.

Priority of allocations: where the priority is determined to service customers; special customers, customers with shorter service process, customers in a hurry etc. can determine the service priorities.

Random Order: there is no particular cause and order for the service.

In order to describe the Queuing process, a number of letters and diagonal lines as A / B / X / Y / Z are used where:

A: the distribution of time intervals of the applicants' arrival; 
B: How to service or the probabilities of service time;

$\mathrm{X}$ : number of channels of service time;

Y: the capacity of the system;

Z: discipline (Kendall, 1953).

\section{Methodology}

To investigate the function of queuing theory in reducing energy consumption in green supply chain, queuing theory was examined in transportation sector of green supply chain in this state we have certainly congestion in the present article.

It is clear that the analysis of more complex systems in green supply chain requires using efficient software in modeling analysis and simulation of supply chain. LINGO software as a powerful tool provides a framework that supply chain system engineers and analysts can simulate and analyze the results obtained from the model development. Following the results analysis, feedbacks can be applied into the system and corrective action can be used in order to improve the efficiency of the supply chain system. The LINGO software makes it possible to analyze the sensitivity and scenario making in the given system.

The aim of this study is to allocate transport fleet in the routes of different centers in supply chain layers using queuing theory.

In the proposed model, the departure and arrival times are stochastic. The number of arrived and served vehicles follows Poisson process and therefore the time between arrivals of two vehicles follows exponential distribution. There exist multiple servers working in parallel. Therefore, the proposed model has flexibility in determining the number of servers that work in parallel.

The system capacity is also unlimited on selected models. So the model M / M / S / $\infty$ / Pri is used. Figure 4 indicates the general form of the given supply chain. 


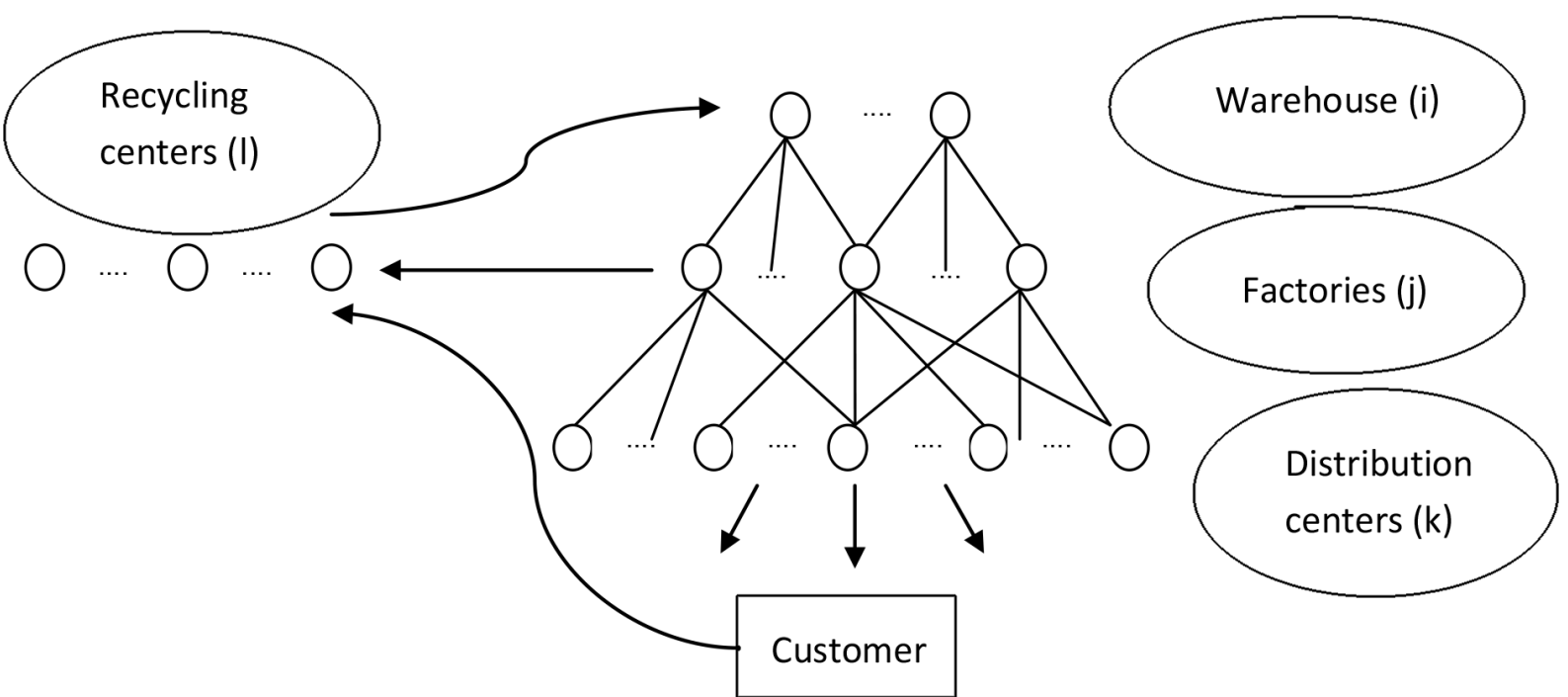

Figure 4. The general form of the given supply chain

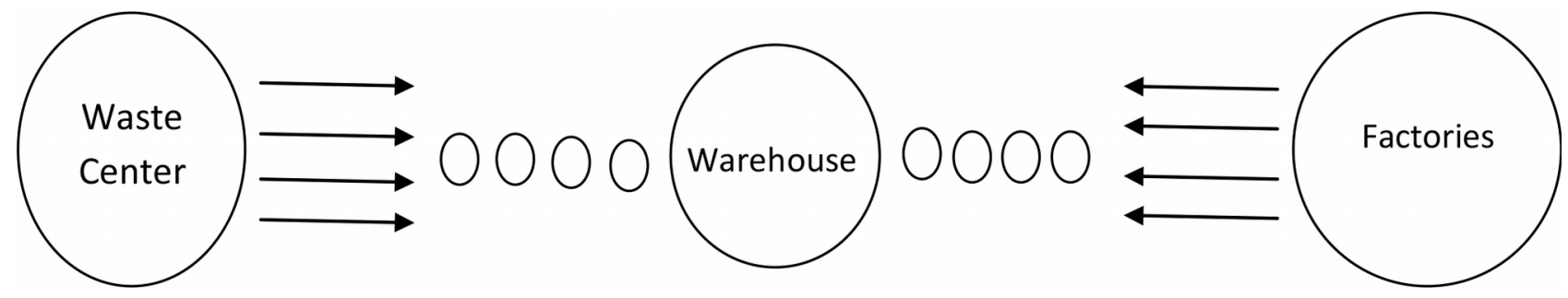

Figure 5. An example of a Queue formed at a center of the supply chain

\section{Mathematical Formulation}

Some assumptions should be considered for modeling the queue:

1. The queue model is as $\mathrm{M} / \mathrm{M} / \mathrm{S} / \infty /$ Pri.

2. Total number of transportation fleet as well as their capacity is specified.

3. The number of servers in each center consists two parts of loading and unloading fleets, which queue systems operate separately.

4. Servers in each loading or unloading centers can be multiple parallel servers.

5. The distance between centers is specified.

6. The discharge rate in centers is directly related to the distance between the centers.

7. The number of parallel servers is fixed and specified in the loading and unloading centers.

8. The quantity of waste which comes from the market to the recycling center is specified.

9. The fleet movement rate between different centers is specified. 
10. The production rate in factories centers is specified.

11. The amount of waste is specified.

12. The amount of the final product should be maintained in the factories in any order is specified in terms of order.

13. The withdrawal rate of discharge machines (unloaded) in each center is fixed.

14. The fleet movement between centers is reciprocating.

15. It is assumed that system is stable in each center:

$$
p=\frac{\text { Arrival rate }}{(\text { Arrival rate }) \times(\text { Service rates })}<1
$$

Indices and model sets are as follows:

I: Warehouses centers

$J:$ Factories centers

$K:$ Distribution centers

$L:$ Recycling centers

The parameters considered in this model include:

$Z$ : Traffic volume between the two centers

$Z_{0}$ : Amount of waste that enters the waste storage from market

gj: Percentage of waste in the factory $j$

$\gamma_{j}$ : Percentage of production rate at the factory $j$

$H_{j}$ : Quantity of products entered into the warehouse after production at the factory $j$

$T N V$ : Total number of fleets in the entire chain

$C V$ : Carrying capacity of the fleet

$\lambda$ : Arrival rate of vehicles to discharge

$\mu$ : Rate of discharged vehicles outflow

$S:$ The number of parallel servers in each center unloading section

$\lambda$ : Fleet arrival rate for loading

$\mu$ : Rate of loaded vehicles withdrawal 
S: The number of parallel servers in each center loading sector

$\pi_{0}:$ Idle percentage in state zero

LQ: Average length of queue

$W Q$ : average waiting time in queue

$W$ : The average waiting time in the system

$P$ : The percentage of servers' or utilization agent's operating time

$D:$ Distance in center $(m)$

T: Transportation time unit per distance unit

$C:$ The percentage of pollutants generated by the operation time of transportation fleet

The decision variables in this model are as follows:

$N V:$ Number of fleets in the different centers between layers of the supply chain

NT: Number of fleet commutes between centers

For this purpose of the present study, the time function is used. C coefficient is used to calculate the consumption of contaminants over time. This means that the shorter the transit and waiting time, the lower the energy consumption.

$\operatorname{MinC}$

MinC

$$
\begin{aligned}
& \left(\sum_{i} \sum_{j} 2 T_{i j} d_{i j} N T_{i j}+\sum_{j} \sum_{k} 2 T_{j k} d_{j k} N T_{j k}+\sum_{j} \sum_{l} 2 T_{j l} d_{j l} N T_{j l}+\sum_{l} \sum_{i} 2 T_{l i} d_{l i} N T_{l i}+\right. \\
& \left.\sum_{i}\left(W_{i} L Q_{i}+\dot{W}_{i} L^{\prime} Q_{i}\right)+\sum_{j}\left(W_{j} L Q_{j}+\dot{W}_{j} L^{\prime} Q_{j}\right)+\sum_{j}\left(W_{k} L Q_{k}\right)+\sum_{k}\left(W_{l} L Q_{l}+\dot{W}_{l} L^{\prime} Q_{l}\right)\right)
\end{aligned}
$$

S.t.

$\sum_{i} \sum_{j} N V_{i j}+\sum_{j} \sum_{k} N V_{j k}+\sum_{j} \sum_{l} N V_{j l}+\sum_{l} \sum_{i} N V_{l i}=\mathrm{TNV}$

$$
\left\{\begin{array}{c}
Z_{i j}=c \\
Z_{j l}=\sigma_{j} \gamma_{j} \sum_{i} Z_{i j} \forall j, l \\
Z_{j k}=\sum_{i} Z_{i j}-\sum_{l} Z_{j l}-H_{j} \forall j, k \\
Z_{l i}=\sum_{j} Z_{j l}+Z_{0} \forall l, i
\end{array}\right.
$$




$$
\begin{aligned}
& \left\{\begin{aligned}
N T_{i j} \cdot N V_{i j} & \geq \frac{Z_{i j}}{C V} \forall i, j \\
N T_{j k} \cdot N V_{j k} & \geq \frac{Z_{i k}}{C V} \forall i, k \\
N T_{j l} \cdot N V_{j l} & \geq \frac{Z_{j l}}{C V} \forall j, l \\
N T_{l i} \cdot N V_{l i} & \geq \frac{Z_{l i}}{C V} \forall l, i
\end{aligned}\right. \\
& \lambda_{i}=\sum_{l} \frac{N V_{l i}}{T_{l i} d_{l i}} \forall i \\
& \dot{\lambda}_{l}=\sum_{i} \frac{N V_{l i}}{T_{l i} d_{l i}} \forall l \\
& \lambda_{j}=\sum_{i} \frac{N V_{i j}}{T_{i j} d_{i j}} \forall j \\
& \dot{\lambda}_{\iota}=\sum_{j} \frac{N V_{i j}}{T_{i j} d_{i j}} \forall i \\
& \lambda_{k}=\sum_{j} \frac{N V_{j k}}{T_{j k} d_{j k}} \forall k \\
& \dot{\lambda}_{J}=\sum_{k} \frac{N V_{j k}}{T_{j k} d_{j k}}+\sum_{l} \frac{N V_{j l}}{T_{j l} d_{j l}} \forall j \\
& \lambda_{l}=\sum_{j} \frac{N V_{j l}}{T_{j l} d_{j l}} \forall l \\
& \left\{\begin{array}{l}
P_{i}=\frac{\lambda_{i}}{s_{i} \mu_{i}} \forall i \\
\dot{P}_{i}=\frac{\dot{\lambda}_{l}}{\dot{s}_{l} \dot{\mu}_{l}} \forall i
\end{array}\right. \\
& \left\{\begin{array}{l}
P_{j}=\frac{\lambda_{j}}{s_{j} \mu_{j}} \forall j \\
\dot{P}_{j}=\frac{\dot{\lambda}_{J}}{s_{\jmath} \dot{\mu}_{J}} \forall j
\end{array}\right. \\
& P_{k}=\frac{\lambda_{k}}{s_{k} \mu_{k}} \forall k \\
& \left\{\begin{array}{l}
P_{l}=\frac{\lambda_{l}}{s_{l} \mu_{l}} \forall l \\
\dot{P}_{i}=\frac{\dot{\lambda}_{l}}{\dot{s}_{l} \dot{\mu}_{l}} \forall l
\end{array}\right.
\end{aligned}
$$




$$
\left\{\begin{array}{l}
\pi_{i}^{0}=\frac{1}{\left[\sum_{n=0}^{S_{i}-1} \frac{\left(\frac{\lambda_{i}}{\mu_{i}}\right)^{n}}{n !}+\frac{\left(\frac{\lambda_{i}}{\mu_{i}}\right)^{S_{i, j, l}}}{S_{i} !\left(1-P_{i}\right)}\right]} \forall i \\
\bar{\pi}_{l}^{0}=\frac{1}{\left[\sum_{n=0}^{S_{l}-1} \frac{\left(\frac{\dot{\lambda}_{l}}{\mu_{l}}\right)^{n}}{n !}+\frac{\left(\frac{\dot{\lambda}_{l}}{\dot{\mu}_{l}}\right)^{S_{l}}}{S_{l, j, l} !\left(1-P_{l}\right)}\right]} \forall i
\end{array}\right.
$$

$$
\left\{\begin{array}{l}
\pi_{j}^{0}=\frac{1}{\left[\sum_{n=0}^{S_{j}-1} \frac{\left(\frac{\lambda_{j}}{\mu_{j}}\right)^{n}}{n !}+\frac{\left(\frac{\lambda_{j}}{\mu_{j}}\right)^{S_{j}}}{S_{j} !\left(1-P_{j}\right)}\right]} \forall j \\
\pi_{J}^{0}=\frac{1}{\left[\sum_{n=0}^{S_{J}-1} \frac{\left(\frac{\dot{\lambda}_{J}}{\mu_{J}}\right)^{n}}{n !}+\frac{\left(\frac{\dot{\lambda}_{j}}{\mu_{J}}\right)^{S_{j}}}{S_{j} !\left(1-P_{j}\right)}\right]} \forall j
\end{array}\right.
$$

$$
\pi_{k}^{0}=\frac{1}{\left[\sum_{n=0}^{S_{k}-1} \frac{\left(\frac{\lambda_{k}}{\mu_{k}}\right)^{n}}{n !}+\frac{\left(\frac{\lambda_{k}}{\mu_{k}}\right)^{S_{k}}}{S_{k} !\left(1-P_{k}\right)}\right]} \forall k
$$

$$
\left\{\begin{array}{l}
\pi_{l}^{0}=\frac{1}{\left[\sum_{n=0}^{S_{l}-1} \frac{\left(\frac{\lambda_{l}}{\mu_{l}}\right)^{n}}{n !}+\frac{\left(\frac{\lambda_{l}}{\mu_{l}}\right)^{S_{l}}}{S_{i} !\left(1-P_{l}\right)}\right]} \forall l \\
\bar{\pi}_{l}^{0}=\frac{1}{\left[\sum_{n=0}^{S_{l}-1} \frac{\left(\frac{\dot{\lambda}_{l}}{\dot{\mu}_{l}}\right)^{n}}{n !}+\frac{\left(\frac{\dot{\lambda}_{l}}{\dot{\mu}_{l}}\right)^{S_{l}}}{\hat{S}_{l} !\left(1-\dot{P}_{l}\right)}\right]} \forall l
\end{array}\right.
$$

$$
\left\{\begin{array}{l}
L Q_{i}=\frac{\left(\frac{\lambda_{i}}{\mu_{i}}\right)^{S_{i}} P_{i, j, l}}{S_{i} !\left(1-P_{i}\right)^{2}} \pi_{i}^{0} \forall i \\
L Q_{l}=\frac{\left(\frac{\dot{\lambda}_{l}}{\dot{\mu}_{l}}\right)^{S_{l}} P_{l, j, l}^{\prime}}{\hat{S}_{l} !\left(1-\dot{P}_{l}\right)^{2}} \pi_{l}^{0} \forall i
\end{array}\right.
$$

$$
\begin{aligned}
& \left\{\begin{array}{l}
L Q_{j}=\frac{\left(\frac{\lambda_{j}}{\mu_{j}}\right)^{S_{j}}{ }^{P_{j}}}{S_{j} !\left(1-P_{j}\right)^{2}} \pi_{j}^{0} \forall j \\
L Q_{J}=\frac{\left(\frac{\dot{\lambda}_{J}}{\mu_{J}}\right)^{\dot{S}_{J}}{ }^{P_{J}}}{\dot{S}_{J} !\left(1-\dot{P}_{j}\right)^{2}} \pi_{j}^{0} \forall j
\end{array}\right. \\
& L Q_{k}=\frac{\left(\frac{\lambda_{k}}{\mu_{k}}\right)^{S_{k}}{ }_{P_{k}}}{S_{k} !\left(1-P_{k}\right)^{2}} \pi_{k}^{0} \forall k
\end{aligned}
$$




$$
\begin{aligned}
& \left\{\begin{array}{l}
L Q_{l}=\frac{\left(\frac{\lambda_{l}}{\mu_{l}}\right)^{S_{l}}{ }^{P_{l}}}{S_{l} !\left(1-P_{l}\right)^{2}} \pi_{l}^{0} \forall l \\
L Q_{l}=\frac{\left(\frac{\dot{\lambda}_{l}}{\dot{\mu}_{l}}\right)^{S_{l} P_{l}}}{\dot{S}_{l} !\left(1-\dot{P}_{l}\right)^{2}} \pi_{l}^{0} \forall l
\end{array}\right. \\
& \left\{\begin{array}{l}
W Q_{i}=\frac{L Q_{i}}{\lambda_{i}} \forall i \\
W Q_{l}=\frac{L \dot{Q}_{l}}{\dot{\lambda}_{\iota}} \forall i
\end{array}\right. \\
& \left\{\begin{array}{l}
W Q_{j}=\frac{L Q_{j}}{\lambda_{j}} \forall j \\
W Q_{J}=\frac{L \dot{Q}_{j}}{\hat{\lambda}_{J}} \forall j
\end{array}\right. \\
& W Q_{k}=\frac{L Q_{k}}{\lambda_{k}} \forall k \\
& \left\{\begin{array}{c}
W Q_{l}=\frac{L Q_{i, j, l}}{\lambda_{i, j, l}} \forall l \\
W Q_{l}=\frac{L Q_{l}}{\grave{\lambda}_{l}} \forall l
\end{array}\right. \\
& \left\{\begin{array}{l}
W_{i}=W Q_{i}+\frac{1}{\mu_{i}} \forall i \\
W_{\iota}=W Q_{\iota}+\frac{1}{\mu_{\iota}} \forall i
\end{array}\right. \\
& \left\{\begin{array}{l}
W_{j}=W Q_{j}+\frac{1}{\mu_{j}} \forall j \\
W_{J}=W Q_{J}+\frac{1}{\mu_{j}} \forall j
\end{array}\right. \\
& W_{k}=W Q_{k}+\frac{1}{\mu_{k}} \forall k \\
& \left\{\begin{array}{l}
W_{l}=W Q_{l}+\frac{1}{\mu_{l}} \forall l \\
W_{l}=W Q_{l}+\frac{1}{\dot{\mu}_{l}} \forall l
\end{array}\right.
\end{aligned}
$$

$$
\text { NT, NV: Integer }
$$

Constraint 1 is the minimizing function with the coefficient $\mathrm{c}$ that minimizes the time of the fleet transportation and the fleet waiting time at the center of the chain.

Constraint 2 determines the entire fleet size in each chain.

Constraints 3-5 indicate the transferring volume between centers. 
Constraints 6-9 show that the coefficient of the number of commutes in the number of fleet in the route between two centers is larger than the ratio of the transferring volume to the capacity of each fleet.

Constraints 10-16 specify the rate of fleet arrival to each center.

Constraints 17-23 indicate the percent of servers' working time.

Constraints 24-30 show the percent of servers' idle time in state zero.

Constraints 30-37 specify the average queue length of each server.

Constraints 37-44 state the average waiting time in queue of each server.

Constraints 45-51 indicate the average waiting time of each fleet in each center.

\section{Numerical Example}

For example, if we consider a supply chain with one warehouse, two plants, two distributors and one recycling center, so that the total number of vehicles is 24 , with a capacity of 10 tons, and the total raw materials transported from warehouse into the factory are approximately 360 tons; also the queue length and waiting time in the queue is obtained according to Table 1, the amount of pollutants produced as a result of serving in each center queue (including loading and unloading) and the fleet movement between the centers is specified in Tables 1 and 2.

\begin{tabular}{|c|c|c|c|c|}
\hline $\begin{array}{l}\text { The amount of } \\
\text { produced pollutants }\end{array}$ & $\mathbf{N V}$ & NT & Destination & Start point \\
\hline$* 200$ & 3 & 8 & $j_{1}$ & $i_{1}$ \\
\hline $2.7 * 310$ & 2 & 6 & $j_{2}$ & $i_{1}$ \\
\hline $8.4 * 250$ & 2 & 4 & $k_{1}$ & $j_{1}$ \\
\hline $4.8^{*} 180$ & 2 & 7 & $k_{2}$ & $j_{1}$ \\
\hline $6.9 * 110$ & 2 & 8 & $k_{1}$ & $j 2$ \\
\hline $18 * 120$ & 3 & 10 & $k_{2}$ & $j 2$ \\
\hline $6.21 * 225$ & 3 & 12 & $l_{1}$ & $j_{1}$ \\
\hline $4.8 * 150$ & 2 & 7 & $l_{1}$ & $j_{2}$ \\
\hline $15 * 80$ & 5 & 5 & $i_{1}$ & $l_{1}$ \\
\hline
\end{tabular}

Table 2. the amount of pollutants generated in the queues of each center due to the queue length

As Table 2 shows, the greatest amount of pollution created at the distribution center 2 is due to its shorter distance with other centers, as well as the service rate provided by the center and fewer parallel servers; by 
increasing the number of servers or using better technology in the center, for loading and unloading fleet, the service rate provided by the center can be raised and the amount of produced emissions can be reduced.

\begin{tabular}{|c|c|c|c|c|c|}
\hline $\begin{array}{l}\text { The amount of pollutants } \\
\text { produced in the queue }\end{array}$ & $W^{\prime}$ & $\mathrm{LQ}^{\prime}$ & WQ & LQ & Centers \\
\hline 2.28 & 5 & 1 & 1.3 & 2 & Warehouse \\
\hline 2.1 & 6 & 0.5 & 1 & 4 & Plant 1 \\
\hline 1.53 & 10 & 0.5 & 0.7 & 3 & Factory \\
\hline 2.7 & - & - & 1.5 & 6 & Distribution 1 \\
\hline 2.97 & - & - & 1.1 & 9 & Distribution 2 \\
\hline 2.25 & 2 & 1 & 0.5 & 11 & Recycling \\
\hline $\begin{array}{l}\text { The amount of pollutants } \\
\text { produced in the queue }\end{array}$ & $\mathbf{W Q}^{\prime}$ & $\mathrm{LQ}^{\prime}$ & WQ & LQ & Centers \\
\hline 2.28 & 5 & 1 & 1.3 & 2 & Warehouse \\
\hline 2.1 & 6 & 0.5 & 1 & 4 & Factory \\
\hline 1.53 & 10 & 0.5 & 0.7 & 3 & Factory 2 \\
\hline 2.7 & - & - & 1.5 & 6 & Distribution 1 \\
\hline 2.97 & - & - & 1.1 & 9 & Distribution 2 \\
\hline 2.25 & 2 & 1 & 0.5 & 11 & Recycling \\
\hline
\end{tabular}

Table 3. The amount of pollutants produced by the transportation fleet according to the distance between the two centers of and the required time

The number of available fleet in each rout as well as the number of commutes needed for carrying the product is shown in Table 3. The amount of pollution, which is produced related to the distance between the centers, and the required time have been determined. As it is known, by increasing the number of fleets, the number of transport on this route, and subsequently, the amount of harmful pollution can be reduced. It should be noted that the correct selection of center locations and their distance from each other is effective and should be carefully studied in the beginning of the establishment of centers.

As presented in Figure 6, the congestion happens in $J_{1}$ and $J_{2}$ areas. 


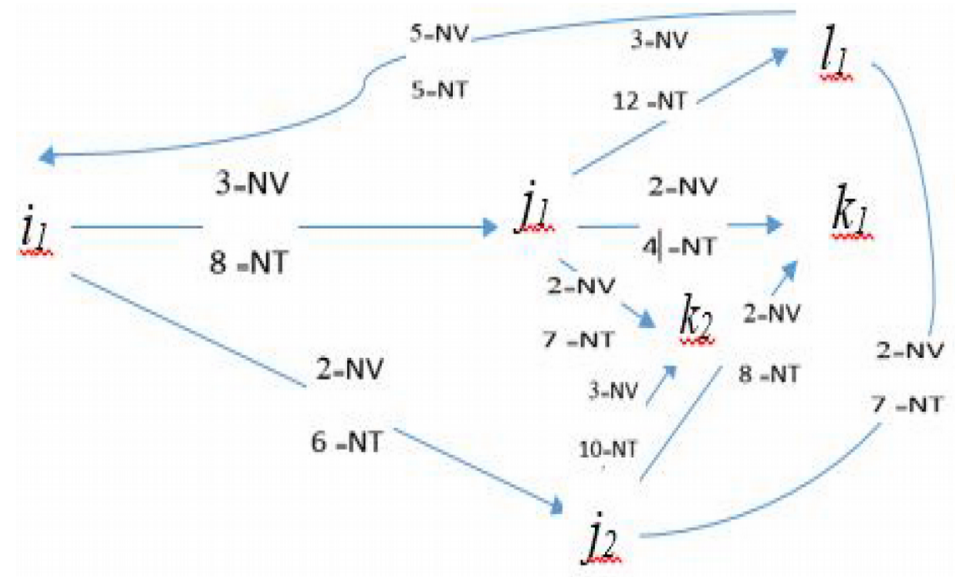

Figure 6. Queue length

By adding the transportation fleet size of the company and therefore eliminating the existing queue in these area, the congestion problem is resolved and consequently the average travel time is reduced.

The findings show that considering queuing theory in loading and unloading of items and also separation of mails and parcels could lead to a considerable reduction in the resulted pollutions.

\section{Conclusion}

Organizations need to use environmental considerations in their supply chain to benefit from green supply chain competitive advantages. One of these considerations is care about optimizing energy consumption due to the limited and irreplaceable resources. Using the queuing theory in the green supply chain management activities gives organizations the opportunity to improve the activities of green supply chain management, such as the purchase of raw materials, production, logistics and external and internal logistics as well as reverse logistics to reduce energy waste. Prioritizing activities in processes related to any subset of green supply chain management, leads to optimizing transportation and waiting time in the processes and subsequently reducing energy consumption. All parameters listed in the survey according to Tables 2 and 3, including the correct locations of centers, the number of available fleet on the track between the centers, as well as the rate of service provided by centers for the fleet, the number of trips between centers, and even the number of service centers and servers in the centers, service providing technology, etc. all can be effective on decreasing emissions. Since each of these parameters can affect the others, each of these parameters and taking them together into account can be effective on reducing pollution in supply chain transportation fleet and can be the subject for the future research. 


\section{References}

Abedi, S., Hamidi, N., \& Parkhan, M. (2011). Probabilistic systems modeling using Markov chain with layout constraints. Journal of Management, 22, $8^{\text {th }}$ year, 66-54.

Adan, I., \& Resing, J. (2002). Queueing Theory. Department of Mathematics and Computing Science, Eindhoven University of Technology.

Allenby, B.R., \& Richards, D.J. (1994). The Greening of Industrial Ecosystems. Washington, DC: National Academy Press.

Amemba, C.S., Nyaboke, P.G., Osoro, A., \& Mburu, N. (2013). Elements of Green Supply Chain Management. European Journal of Business and Management, 5(12), 51-61.

Arena, U., Mastellone, M.L., \& Perugini, F. (2003). The Environmental Performance of Alternative Solid Waste Management Options: A Lifecycle Assessment Study. Chemical Engineering Journal, 96, 207-222. https://doi.org/10.1016/j.cej.2003.08.019

Ashley, S. (1993). Designing for the Environment. Mechanical Engineering, 115(3), 53-55.

Beamon, B. (1999). Designing the Green Supply Chain. Logistics Information Management, 12(4), 332-342. https://doi.org/10.1108/09576059910284159

Berman, O., \& Krass, D. (2015). Stochastic location models with congestion. Location science. Springer. 443486. https://doi.org/10.1007/978-3-319-13111-5_17

Boks, C., \& Stevels, A. (2007). Essential Perspectives for Design for Environment. Experiences from the Electronics Industry. International Journal of Production Research, 45(18-19), 4021-4039. https://doi.org/10.1080/00207540701439909

Bowen, F.E., Cousins, P.D., Lamming, R.C., \& Faruk, A.C. (2001). Horses for Courses: Explaining the Gap between the Theory and Practice of Green Supply. Greener Management International, 35, 41-60. https://doi.org/10.9774/GLEAF.3062.2001.au.00006

Carter, C.R., Ellram, L.M. (1998). Reverse Logistics: A Review of theLiterature and Framework for Future Investigation. Journal of Business Logistics, 19, 85-102.

Chen, X.M., Xiong, C., He, X., Zhu, Z., \& Zhang, L. (2016). Time-of-day vehicle mileage fees for congestion mitigation and revenue generation: A simulation-based optimization method and its real-world application. Transportation Research Part C: Emerging Technologies, 63, 71-95. https://doi.org/10.1016/j.trc.2015.12.001 
Chiu, Y.-C., Bottom, J., Mahut, M., Paz, A., Balakrishna, R., Waller, T., \& Hicks, J. (2011). Dynamic traffic assignment: A primer. Transportation Research E-Circular (E-C153).

De Ron, A., \& Penev, K. (1995). Disassembly and Recycling of Electronic Consumer Products: An Overview. Technovation, 15, 407-421. https://doi.org/10.1016/0166-4972(95)96597-M

Ding, W., Tang, L., \& Ji, S. (2016). Optimizing routing based on congestion control for wireless sensor networks. Wireless Networks, 22(3), 915-925. https://doi.org/10.1007/s11276-015-1016-y

Ernst, A.T., \& Krishnamoorthy, M. (1996). Efficient algorithms for the uncapacitated single allocation p-hub median problem. Location Science, 4(3), 139-154. https://doi.org/10.1016/S0966-8349(96)00011-3

Fathian, M., Jouzdani, J., Heydari, M., \& Makui, A. (2016). Location and transportation planning in supply chains under uncertainty and congestion by using an improved electromagnetism-like algorithm. Journal of Intelligent Manufacturing, 1-18. https://doi.org/10.1007/s10845-015-1191-9

Fortes, J. (2009). Green Supply Chain Management: A Literature Review. Otago Management Graduate Review, 9, 51-62.

Friesz, T.L., Bernstein, D., \& Kydes, N. (2004). Dynamic congestion pricing in disequilibrium. Networks and Spatial Economics, 4(2), 181-202. https://doi.org/10.1023/B:NETS.0000027772.43771.94

Geramianfar, R., Pakzad, M., Golhashem, H., \& Tavakkoli-Moghaddam, R. (2013). A multi-objective hub covering location problem under congestion using simulated annealing algorithm. Uncertain Supply Chain Management, 1(3), 153-164.

Guide, V.D.R., \& Srivastava, R. (1998). Inventory Buffers in Recoverable Manufacturing. Journal of Operations Management, 16, 551-568. https://doi.org/10.1016/S0272-6963(97)00024-7

Gupta, M.B., Khanna, R.B. (2006). Quantitative Techniques for Decision Making (2nd Ed.). New Delhi: Prentice Hall of India.

Hanna, M.D., \& Newman, W.R. (1995). Operations and Environment: an Expanded Focus for TQM. International Journal of Quality and Reliability Management, 12, 38-53. https://doi.org/10.1108/02656719510089984

Heravani, J.L., Nemati, N., Bozorgipour, R., \& Hosseininegad, Z. (2005). Yield Stability of some Promising Cultivars and Hybrids of Cotton (Gossypium birsutum) in Northern Khorasan and Moghan Plain.

Imani, D.M., \& Ahmadi, A. (2009). Green Supply Chain Management: a new strategy for gaining competitive advantage. Journal of Automobile Engineering and related industries, 10, 14-19. 
Inoue, R., Miyashita, A., \& Sugita, M. (2016). Mining spatio-temporal patterns of congested traffic in urban areas from traffic sensor data. Paper presented at the Intelligent Transportation Systems (ITSC), 2016 IEEE 19th International Conference on. https://doi.org/10.1109/ITSC.2016.7795635

Jafarnejad, A. (1991). Queuing theory. Journal of Management Science, 13(0), 36-42.

Jouzdani, J., \& Fathian, M. (2016). Hybrid Electromagnetism-Like Algorithm for Dynamic Supply Chain Network Design under Traffic Congestion and Uncertainty. Mathematical Problems in Engineering. https://doi.org/10.1155/2016/2498616

Kelle, P., \& Silver, E.A.. (1989). Forecasting the Returns of Reusable Containers. Journal of Operations Management, 8(1), 17-35. https://doi.org/10.1016/S0272-6963(89)80003-8

Kendall, M. (1953). The Analysis of Economic Time Series - Part 1: Prices. Journal of the Royal Statistical Society, 96, 11-25. https://doi.org/10.2307/2980947

Kian, R., \& Kargar, K. (2016). Comparison of the formulations for a hub-and-spoke network design problem under congestion. Computers \& Industrial Engineering, 101, 504-512.

https://doi.org/10.1016/j.cie.2016.09.019

Min, H., Ko, H.J., \& Ko, C.S. (2006). A Genetic Algorithm Approach to Developing the Multi-echelon Reverse Logistics Network for Product Returns. Omega, 34, 56-69. https://doi.org/10.1016/j.omega.2004.07.025

Nagorney, A., \& Toyasaki, F. (2005). Reverse Supply Chain Management and Electronic Waste Recycling: A Multi-tiered Network Equilibrium Framework for E-cycling. Transportation Research Part E: Logistics and Transportation Review, 41, 1-28. https://doi.org/10.1016/j.tre.2003.12.001

Nasseri-Taheri, M. (2006). Green supply chain, a new strategy in achieving competitive advantage in the 21st century. New Trade and Economy Quarterly, 6, 146-132.

Navin-Chandra, D. (1991). Design for Environmentability. Design Theory and Methodology, 31, 99-124.

Olfat, L., Khatami-Firouz, A., \& Khodaverdi, R.A. (2011). The requirements for realization of green supply chain management in the automotive industry of Iran. Journal of Management Sciences in Iran, 21, 123-140.

Pohlen, T.L., \& Farris, M.T. (1992). Reverse Logistics in Plastic Recycling. International Journal of Physical Distribution and Logistics Management, 22, 35-47. https://doi.org/10.1108/09600039210022051 
Rahimi, Y., Tavakkoli-Moghaddam, R., Mohammadi, M., \& Sadeghi, M. (2016). Multi-objective hub network design under uncertainty considering congestion: An $\mathrm{M} / \mathrm{M} / \mathrm{c} / \mathrm{K}$ queue system. Applied Mathematical Modelling, 40(5), 4179-4198. https://doi.org/10.1016/j.apm.2015.11.019

Rao, P., \& Holt, D. (2005). Do Green Supply Chains leadtoCompetitiveness and Economic Performance? International Journal of Operations and Production Management, 25(9), 898-916. https://doi.org/10.1108/01443570510613956

Roy, R., \& Whelan, R.C. (1992). Successful Recycling through Value-ChainCollaboration. Long Range Planning, 25, 62-71. https://doi.org/10.1016/0024-6301(92)90009-Q

Sadjadi, S.J., Soltani, R., \& Eskandarpour, A. (2014). Location based treatment activities for end of life products network design under uncertainty by a robust multi-objective memetic-based heuristic approach. Applied Soft Computing, 23(0), 215-226. https://doi.org/10.1016/j.asoc.2014.06.028

Sarkis, J. (2006). Greening the Supply Chain. Springer-Verlag London Limited. https://doi.org/10.1007/1-84628$299-3$

Sarkis, J., \& Cordeiro, J. (2001). An Empirical Evaluation of Environmental Efficiencies and Firm Performance: Pollution Prevention VersusEnd-of Pipe Practice. European Journal of Operational Research, 135, 102-113. https://doi.org/10.1016/S0377-2217(00)00306-4

Shih, L. (2001). Reverse Logistics System Planning for Recycling Electrical Appliances and Computers in Taiwan. Resources, Conservation and Recycling, 32, 55-72. https://doi.org/10.1016/S0921-3449(00)00098-7

Srivastava, S.K. (2007). Green Supply-Chain Management: A State-of-The-Art Literature Review. International Journal of Management Reviews, 9(1), 53-80. https://doi.org/10.1111/j.1468-2370.2007.00202.x

Srivastava, S.K., \& Srivastava, R.K. (2006). Managing Product Returns for Reverse Logistics. International Journal of Physical Distribution and Logistics Management, 36, 524-546.

https://doi.org/10.1108/09600030610684962

Stallings, W. (2000). Queuing Analysis. WilliamStallings.com/StudentSupport.html

Stock, J. (1998). Development and Implementation of Reverse Logistics Programs. Oak Brook: Council of Logistics Management.

Tibben-Lembke, R.S. (2002). Life afterDeath: Reverse Logistics and the Product Life Cycle. International Journal of Physical Distribution and Logistics Management, 32, 223-244. 
Van Der Laan, E.A., \& Salomon, M. (1997). Production Planning and Inventory Control with Remanufacturing and Disposal. European Journal of Operations Research, 102, 264-278. https://doi.org/10.1016/S0377-2217(97)00108-2

Vass, H., \& Szabo, Z.K. (2015). Application of Queuing Model to Patient Flow in Emergency Department. Case Study. Procedia Economics and Finance, 32, 479-487. https://doi.org/10.1016/S22125671(15)01421-5

White, C.D., Masanet, E., Rosen, C., \& Beckman, S. (2003). Product Recovery with Some Byte: An Overview of Management Challenges and Environmental Consequences in Reverse Manufacturing for the Computer Industry. Journal of Cleaner Production, 11(4), 445-458. https://doi.org/10.1016/S09596526(02)00066-5

Wu, H.J., \& Dunn, C.S. (1995). Environmentally Responsible Logistics Systems. International Journal of Physical Distribution and Logistics Management, 25(2), 20-38. https://doi.org/10.1108/09600039510083925

Zangui, M., Yin, Y., \& Lawphongpanich, S. (2015). Sensor location problems in path-differentiated congestion pricing. Transportation Research Part C: Emerging Technologies, 55, 217-230.

https://doi.org/10.1016/j.trc.2015.01.012

Zhang, H.C., Kuo, T.C., Lu, H., \& Huang, S.H. (1997). Environmentally Conscious Design and Manufacturing: A State of the Art Survey. Journal of Manufacturing Systems, 16, 352-371. https://doi.org/10.1016/S0278-6125(97)88465-8

Zhang, R., Rossi, F., \& Pavone, M. (2016). Routing Autonomous Vebicles in Congested Transportation Networks: Structural Properties and Coordination Algorithms. Mar. https://doi.org/10.15607/rss.2016.xii.032

Journal of Industrial Engineering and Management, 2017 (www.jiem.org)

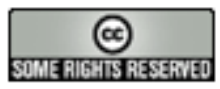

Article's contents are provided on an Attribution-Non Commercial 3.0 Creative commons license. Readers are allowed to copy, distribute and communicate article's contents, provided the author's and Journal of Industrial Engineering and Management's names are included. It must not be used for commercial purposes. To see the complete license contents, please visit http://creativecommons.org/licenses/by-nc/3.0/. 